\title{
Safety-at-work competences as a driver of corporate social responsibility
}

\author{
Adam Górny ${ }^{1, *}$ \\ ${ }^{1}$ Poznań University of Technology, Faculty of Management Engineering, Chair of Ergonomics and \\ Quality Management, 11 Strzelecka Str., PL-60-965 Poznań, Poland
}

\begin{abstract}
In order to operate effectively in a continuously changing and frequently turbulent markets, companies must account for the needs and expectations of both their management and lower-ranking employees. To that end, it is essential that business organizations identify ways to adopt changes that will guarantee their success. One way to improve the market position of a company is to employ the principles of corporate social responsibility. A key requirements as well as a key area of such responsibility is occupational health and safety, whose guidelines fall within the scope of the overall practices enshrined in labor law. A prerequisite for the effective fulfillment of such requirements is to secure competent contractors who will undertake all measures associated with this field. The article notes the issue and examines it against the standards set forth in ISO 26000. The author demonstrates the need to acquire competences that will enable the concerned company to ensure the safe performance of work and the fulfillment of occupational health and safety requirements in conformity with the principles of corporate social responsibility. Only by embracing the rules of CSR under such an approach will a business be able to achieve the desired outcomes.
\end{abstract}

\section{Introduction}

In the course of their activities, today's business organizations increasingly follow the guidelines of corporate social responsibility. To become socially responsible in their day-today business, enterprises need to strive to fulfill the expectations of all of their stakeholders. They should therefore examine multiple aspects of any relevant issue [1].

One significant area having a major influence on the effectiveness of an organization's efforts is occupational safety. Safety should be seen as a necessary condition for an enterprise's success. To attain safety, a company has to create worker-friendly working conditions that will enable its workers to function properly in the working environment [2].

Any actions depend heavily on man seen as both their beneficiary and their performer. The job of humans is to take measures aimed at ensuring proper conditions in the working environment [3] and strive to make such measures as effective as possible [4-5]. The consequence of such efforts is a reduction in loads and, ultimately, the lowering of accident

" Corresponding author: adam.gorny@put.poznan.pl 
rates and risk levels [6-7], which in turn boosts the bottom line providing the company with a competitive advantage [4].

\section{Characteristics of issues in question}

\subsection{Corporate social responsibility as an approach to doing business}

The corporate social responsibility (CSR) can be defined as the voluntary incorporation of the social and ecological dimension into any activities and structures of a business organization relating to their stakeholders [8-9]. A socially responsible enterprise needs to do its business in keeping with the expectations of any concerned parties to ensure multifaceted development of humans [10]. A substantial role in the development of a company that abides by the principles of CSR played by ethical values, respect for both the natural environment, and people (employees).

In addition, an organization's strategy commonly incorporates the pursuit of sustainable growth. Such growth depends heavily on satisfying human needs. Research finds that companies that comply with CSR guidelines tend to experience improvements in the efficiency, quality and effectiveness of their workers $[2,11]$.

When embracing CSR principles, businesses should recognize the limitations of humans who need to be seen as a critical factor for improvement that is vital for fulfilling customer needs and expectations [8, 12-13]. Commonly referred to as the human factor, people are of great importance for ensuring the effective and efficient achievement of an organization's objectives. The human factor determines the ability to adopt the changes that result from the efficient management of every corporate function. In order for CSR to enable a business to accomplish its intended aims, corporate social responsibility has to be incorporated into its strategy, its elements permanently implanted into the company's key operating areas. One can safely assume that some such criteria pertain to the working environment.

\subsection{Occupational safety as a precondition for effective task completion}

Occupational safety is traditionally, viewed as the status of working conditions; working environments, work design and employee behaviors that ensures the required level of health and life protection against risks arising in the working environment [4-5].

Occupational safety may be seen as the absence of any unacceptable risks and untoward factors that result in damage. In this sense, companies seeking to safeguard safety and protect worker health must adopt measures and solutions that comply with relevant laws and regulations while accounting for the role and significance of employees for ensuring the companies' effective operation.

The aim behind occupational safety improvement measures is to achieve an equilibrium between man, machine and the working environment that will ensure that all three operate reliably in unison. To achieve that, it is crucial to account for methodological complexity and apply complementary actions for people and technologies covering social, technical, economic and organizational considerations. Success in ensuring safety and reducing strains may depend on the degree of success in the achievement of various objectives associated with work design, technical measures, the use of personal protection equipment, etc. In pursuing such objectives, organizations need to be mindful of the specific working conditions and the conditions in which man operates in the working environment and at the workstation. What is essential is that enterprises recognize all factors that may potentially exert a negative influence on working conditions. In particular, emphasis should be placed on the factors that can be modified to achieve the desired outcomes. 
The prime goal in employing improvement measures is to mitigate threats and strains to optimize loads and ultimately boost working effectiveness. Success in protecting and promoting humans naturally, can be, linked with innovation. Many of the criteria that are vital for innovative pursuits tie inextricably to the ability to ensure a safe working environment or reduce untoward strains during the performance of work duties. What is critical is for the process to be continuous and to create conditions for the growth of the concerned organization that conform to the principles of corporate social responsibility.

\subsection{Worker competences as a determinant for the adoption of occupational safety solutions}

Competences may be viewed as a body of theoretical knowledge and practical skills that support work performance. Competent individuals complete their tasks more easily, performing more efficiently and effectively and are therefore more likely to meet relevant expectations.

Pursuant to ISO 9001 [14], competences may be seen as a demonstrated ability to apply knowledge and employ skills. Defined in this way, competences can be designed as:

- Having knowledge in a given field (I know what to do),

- Skills (I know how to do it),

- Attitude (I want to and am prepared to use my knowledge),

- Personality traits.

A competent person, i.e. one that satisfies the above criteria, is one empowered to act and make decisions and qualified to make judgments and offer opinions and assessments [15]. With respect to the subject matter of this article, the actions of a person who is competent in a specific field should respect the boundaries and satisfy the requirements that are in place in a given community and that make it possible to operate in a specific environment. Workers charged with the performance of tasks associated with specific threats, be it to themselves and/or other workers in their organization as well as any individuals from outside the company, should have pertinent competences documented with educational and training credentials and/or experience that matches specific requirements [15].

According to ILO guidelines [16], an employer should have or ensure occupational health and safety competences that are sufficient to identify threats, eliminate or reduce occupational risks as well as adopt occupational health and safety solutions. Such competences should be viewed as mandatory for persons responsible for safety. Among the required competences, emphasis should be placed on such knowledge and skills as allow one to [17]:

- Perform work in a manner that eliminates threats seen as a source of potential risks,

- Assess the impact of any threats that have not been eliminated,

- Eliminate threats at source and prevent their spreading,

- Adjust working conditions and work processes to the individual needs and capacities of workers,

- Employ state-of-the-art technologies and the latest technical solutions and organizational measures as available and applicable in particular circumstances,

- Replace dangerous technological processes, high-risk equipment, hazardous substances and other dangerous materials with safer / less dangerous equivalents,

- Give priority to the use of collective protective measures before resorting to personal protection equipment that may cause secondary threats and strains,

- Train and instruct workers in occupational health and safety ensuring they are capable of performing their work safely and make proper use of improvement measures. 


\section{Conditions for adopting social responsibility}

\subsection{The essence of embracing social responsibility}

Under the current paradigm, organizations need to adopt growth strategies aligned with new sources of competitive advantages that will allow them to respond rapidly to changes in the global environment. Although the task may be daunting, a company that is aware of its needs and abilities will find it achievable. The need to ensure an ever-greater level of competitiveness may be considered as helpful for an organization's market credibility. To become increasingly competitive, enterprises should engage on multiple fronts in actions aimed at establishing good relationships with their stakeholders, including their employees. Such actions become a foundation and define guidelines for the performance of tasks in conformity with CSR principles [11-12].

One of the factors that critically affect success in becoming a socially responsible organization is occupational health and safety, which defines the ability to operate effectively in a specific environment. The extent to which a company succeeds in keeping its workers safe translates into the level of its social responsibility defined based on measures taken to achieve the status of a safe organization that cares for the growth of its environment and that pursues tasks in keeping with working environment requirements.

Occupational health and safety is one of the main areas of practice in the general field of work. Its place in the structure of labor law practices is presented in Table 1.

Table 1. Labor-law related practices significant for the assumption of proper social responsibility.

\begin{tabular}{|c|c|c|}
\hline No. & $\begin{array}{l}\text { Key areas and } \\
\text { issues }\end{array}$ & Requirement area \\
\hline 1 & $\begin{array}{l}\text { Employment } \\
\text { and } \\
\text { employment } \\
\text { relationships }\end{array}$ & $\begin{array}{l}\text { Employment is subject to laws, which impose the same obligations on } \\
\text { workers and employers. The key responsibility of an organization is to } \\
\text { adopt solutions that will eliminate the danger of benefiting from unfair } \\
\text { employment practices that involve exploitation and fraud. }\end{array}$ \\
\hline 2 & $\begin{array}{l}\text { Terms of } \\
\text { employment } \\
\text { and } \\
\text { employment } \\
\text { relationships }\end{array}$ & $\begin{array}{l}\text { Terms of employment including pay, work and rest times, disciplinary } \\
\text { practices, redundancy practices, maternity protections, etc. affect the } \\
\text { quality of life of both workers and their families. The scope of such } \\
\text { terms makes it necessary to approach implementation in a fair and } \\
\text { attentive fashion. }\end{array}$ \\
\hline 3 & Social dialogue & $\begin{array}{l}\text { Social dialogue applies to issues of popular interest, including economic } \\
\text { and social matters. It requires the recognition that both the employer and } \\
\text { the employees have shared as well as opposed interests. Such dialogue } \\
\text { can be used to design competence development programs that help } \\
\text { people improve and become more efficient at work or to reduce adverse } \\
\text { impacts of social change that affects organizations. }\end{array}$ \\
\hline 4 & $\begin{array}{l}\text { Occupational } \\
\text { health and } \\
\text { safety }\end{array}$ & $\begin{array}{l}\text { The field of occupational health and safety concerns measures aimed at } \\
\text { maintaining workers in maximum physical, mental and social fitness. } \\
\text { The occupational health and safety requirements adopted in } \\
\text { organizations protect workers against the health risks that arise in the } \\
\text { working environment and help adjust that environment to reflect } \\
\text { employees' physical and mental capabilities. }\end{array}$ \\
\hline 5 & $\begin{array}{l}\text { Human } \\
\text { improvement } \\
\text { and workplace } \\
\text { training }\end{array}$ & $\begin{array}{l}\text { The measures taken should guarantee the improvement of humans that } \\
\text { is vital for the growth of society. Initiatives are launched to boost the } \\
\text { potential of employees and improve their fitness for work. To achieve } \\
\text { this, it is essential to continually increase and improve experience, } \\
\text { competences and qualifications. }\end{array}$ \\
\hline
\end{tabular}




\subsection{Occupational safety as a field for adopting social responsibility}

The occupational health and safety of workers can be viewed as being of particular significance for the proper operation of businesses. This applies in particular to the requirements that go beyond the measures mandated by law. The outcomes achieved through social responsibility can be viewed as the internal and external impacts of a company. To ensure a safe environment for its workers, measures that address the internal impacts are particularly significant. These include $[4,7-8,16,18]$ :

- Developing, implementing and maintaining occupational safety rules in the recognition that strict safety standards and financial and organizational concerns within enterprises complement one another,

- Recognizing that the rules for the development of occupational health and safety principles rely on the involvement and commitment of workers, who are entitled to define and voice their own expectations regarding the way their work is to be performed,

- Properly applying occupational health and safety rules, including respect for the hierarchy of methods for eliminating threats inherent in working conditions,

- Assessing and monitoring risks and adopting best practices to eliminate threats or mitigate their adverse impact on workers,

- Ensuring proper communication to guarantee that any concerned persons are aware of the applicable rules and ways to comply with the adopted procedures that are based on legal regulations and good practices,

- Ensuring access to the required personal protective equipment for the prevention of injuries, occupational diseases and accidents at work,

- Proper and effective emergency responses,

- Recording and investigating all incidents and issues relating to safety at work with a view to eliminating them, preventing their recurrence or mitigating their impact,

- Eliminating psychological and social threats occurring at the work place and leading or contributing to stress and any related health conditions,

- Gaining the ability to properly train all workers regardless of the form of and legal basis for their employment,

- Allowing worker involvement in health and safety decisions,

- Taking measures to boost safety while protecting any persons charged with conducting such measures and responsible for their implementation from any negative consequences.

It is equally critical to ensure that the measures taken are comprehensive. Such an approach is particularly crucial in organizations in which irregularities are of a complex nature.

A key consideration in such measures is the organization's internal working environment. Factors that appear in such an environment are essential for assessing the conformity of a working environment with the optimal requirements for a given category of work task performance. Viewed in such a manner, the principles of corporate social responsibility (CSR) allow one to ensure an optimal approach to the loads in the working environment. The principles extend to all significant areas that fall within the category of sustainable growth. If adopted properly, they ensure business growth while promoting a proper quality of life for the workers, in the local community and in the business environment at large.

Every organization has a responsibility for ensuring occupational safety. An organization's size often determines its ability to adopt better or worse OHS practices [19]. The measures taken are intended primarily to ensure the protection of health and the establishment of safety during the performance of work. Proper work design and the adoption of adequate technical solutions help not only to enhance the working environment but also to boost the effectiveness of the labor force. A precondition for the achievement of the desired outcomes is to select the right solutions and implement them in an appropriate manner. 


\section{Competences as a safety driver within the framework of social responsibility}

Changing environments force the organizations that abide by the rules of social responsibility to search for new areas of improvement that will provide them with benefits. Many find it advantageous and critical to examine the specific nature of the human factor in such a search. The human factor proves to be an ever more vital driver of enterprise growth. Organizations that fail to account for the human aspect of their operations find it impossible to adopt modern enterprise growth concepts. However, success in these fields requires specific measures aimed at achieving the desired outcomes and genuine commitment thereto on the part of the organization [3].

Seen as a factor in labor practices, safety depends on a company's competences needed to ensure that work is performed safely and adopt the principles of corporate social responsibility. The need for such competences arises across a wide range of areas that are:

- Necessary for adopting social responsibility,

- Necessary for ensuring occupational safety,

- Instrumental in implementing OHS requirements within the framework of social responsibility principles.

The related interrelationships are summarized in Figure 1.

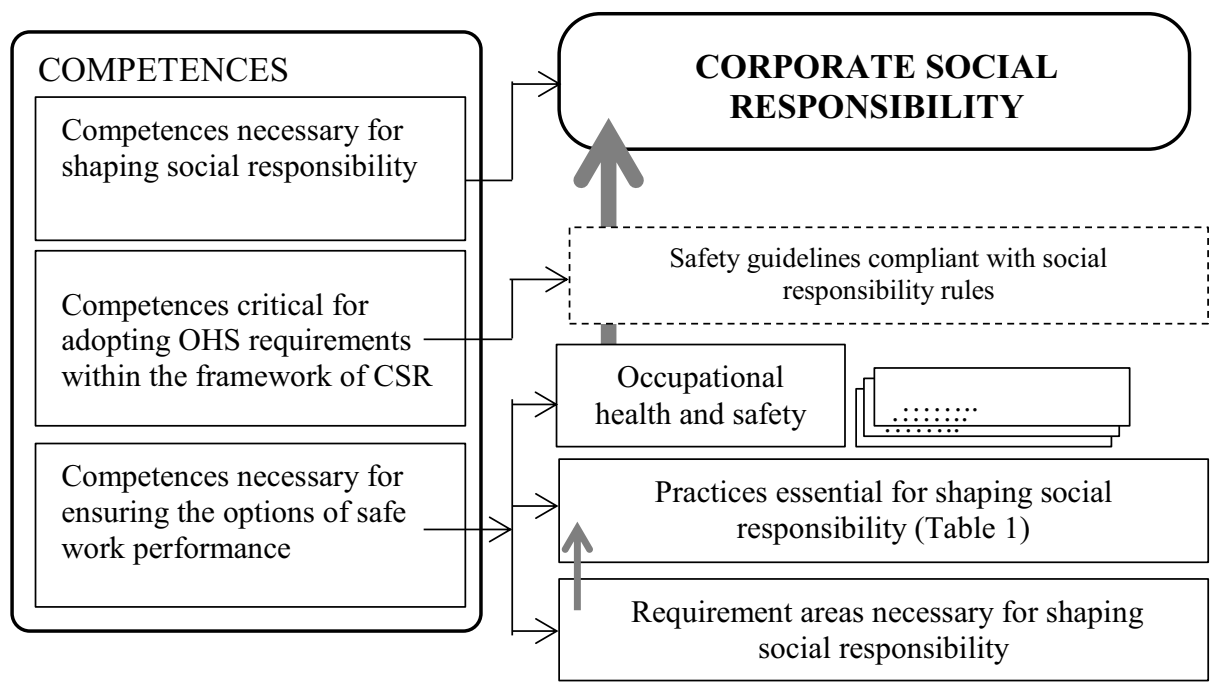

Fig. 1. Interrelationships among competence requirements in the fields of occupational health and safety and corporate social responsibility.

Competences essential for ensuring the effective performance of work among one's employees can be considered as a prerequisite for safety improvement. In actual practice, it is frequently difficult to reconcile business growth with occupational health and safety rules, as laid down in relevant regulations. Despite many advanced safeguards in workplaces, regular inspections and preventive measures, accident rates remain unaffected or even continue to rise [20-21]. Threats to human life and health frequently underrated due to insufficient awareness among both the workers and their employers. It is therefore even more necessary to boost the currently low occupational health and safety levels. Note also that organizations ignorant of the risks of major failures and that underestimate injury risks do not feel motivated to detect threats and undertake preventive measures [2]. Under such circumstances, CSR can be seen as a factor that urges organizations to take action. 
Studies in various fields of business activities find that CSR helps improve the quality of life, of which the human working environment is an integral part [1, 22-23]. CSR affects relationships with workers, the building of trust and the implementation of voluntary measures that enable workers to grow personally and obtain the required qualifications. Such efforts produce the positive synergy effect of reducing losses by lowering the number and severity of accidents [24]. These benefits all parties involved in the organization's activities.

\section{Conclusions}

An effort to comply with OHS requirements with a view to adopting the principles of corporate social responsibility requires adequate solutions. The outcomes of such an approach to the protection of health includes:

- A level of work comfort that guarantees employee health,

- Conformity with the principles of safety in employment resulting from the proper treatment of workers and the protection of human rights,

- Providing employees with a free choice of their preferred form of employment,

- Care for society and the strife to prevent any adverse impact of the organization's business.

To a varying degree and extent, the multiple safety factors include the level of accident hazard. In practice, the likelihood of an accident occurring depends on factors linked to an organization's ability to ensure proper performance of occupational tasks. Such factors include the competences required to conduct work. To incorporate CSR rules in the recognized working environment matrix of safety factors, enterprises need to establish proper relationships that reflect the expectations of all concerned parties.

In practice, the most crucial feature of the new approaches, as adopted by today's businesses, is to remain open to change and flexible, which supports the validity of the above precepts. Therefore, all aspects pertinent to creating a proper working environment appear to be critical and need to be considered in adopting new solutions. It is also vital to identify the requirements of the concerned parties, including a company's employees for whom working conditions are a significant job satisfaction criterion.

\section{References}

1. E. Ozdora-Aksak, M. A. Ferguson, S. A. Duman, Public Relations Review, 42(1), 79 (2016)

2. A. Kawecka-Endler, B. Mrugalska, Advances in Social and Organizational Factors, Advances in Human Factors and Ergonomics Series, 672, AHFE (2012)

3. A. Górny, Procedia Manufacturing, 3, 4700 (2015)

4. A. Górny, MATEC Web of Conferences (the 4th International Conference on Computing and Solutions in Manufacturing Engineering 2016, vol. 94, no 04011 (2017)

5. A. Górny, Occupational Safety and Hygiene, SHO 2016, 105, Guimarães (2016)

6. A. Górny, 2015, Occupational Safety and Hygiene, SHO 2015, 143, Guimarães (2015)

7. M. Rembiasz, MATEC Web of Conferences (the 4th International Conference on Computing and Solutions in Manufacturing Engineering 2016, vol. 94, no 07009 (2017)

8. ISO 26000:2010 (PN-ISO 26000:2012), Guidance on social responsibility, PKN, Warsaw (2012)

9. Green Paper for Promoting a European Framework for Corporate Social Responsibility, $\operatorname{COM}(2002), 366$ final, Brussels

10. Communication for Commission to the European Parliament, the Council and the European Economic and Social Committee Implementing the partnership for growth and jobs: Making Europe a pole of excellence on Corporate Social Responsibility, Commission of the European Communities, $\operatorname{COM}(2006), 136$ final, Brussels 
11. Bernal-Conesa, J., Briones-Peñalver, A., De Nieves-Nieto, C., Eur. J. of Management and Business Economics, 25(3), 121 (2016)

12. A. Grover, Procedia - Social and Behavioral Sciences, 157, 103 (2014)

13. R. Kudłak, K. Y. J. Low, Long Range Planning, 48(3), 215 (2015)

14. EN ISO 9001: 2015 (PN-EN ISO 9001: 2015-10), Quality management systems. Requirements, PKN, Warsaw (2015)

15. PN-N-18001:2004, Systemy zarządzania bezpieczeństwem i higieną pracy. Wymagania, PKN, Warsaw (2004)

16. Guidelines on occupational safety uidelines on occupational safety and health management systems and health management systems ILO-OSH 2001, International Labour Office, Geneva (2001)

17. Council Directive 89/391/EEC of 12 June 1989 on the introduction of measures to encourage improvements in the safety and health of workers at work, OJ L 183, 29.6.1989, pp. 1-8, as amended

18. A. Grzelczak, A. Borowiec, A. Górny, Foresight przedsiębiorstw, vol. 2: Zastosowanie metodyki myślenia sieciowego, Wydawnictwo Politechniki Poznańskiej, Poznań (2013)

19. H. Nordlöf, B. Wiitavaara, H. Högberg, R. Westerling, Safety Science, 95, 92 (2017)

20. Accidents at work and work-related health problems, Central Statistical Office, Warsaw (2014)

21. Working condition in 2015, Central Statistical Office, Warsaw (2016)

22. H. L. Kim, Y. Rhou, M. Uysal, N. Kwon, Int. J. of Hospitality Management, 61, 26 (2017)

23. Y. Rhou, M. Singal, Y. Koh, Int. J. of Hospitality Management, 57, 30(2016)

24. K. Čarnogurský, A. Diačiková, A. Ďaňková, M. Lach, Procedia Economics and Finance, 34, 244 (2015) 